\title{
The Gender Role in the Educational Empowerment of Migrant Families from Eastern Europe and Post-Soviet Countries
}

\author{
NINA IVASHINENKO \\ Lobachevsky State University of N. Novgorod, Russia \\ VALENTINA SHATALINA \\ Russian Academy of Education, Russia
}

\begin{abstract}
This paper analyses the influence of gender roles in educational empowerment, and the motivation placed on children from migrant families of ethnic Russian-speaking minority school communities and their everyday practices. Interviews with parents and teachers were conducted, and observations of participants were made in Glasgow, Edinburgh, Aberdeen and Dundee schools.

The findings show how gender roles that are functioning in migrant families are linked with building educational attitudes, and explore the mother's influence on children's educational motivation. Perspectives of these influences on educational empowerment are drawn, and this paper discusses how they are strongly connected with falling levels of poverty and positive integration into the local society of migrant children. These issues are especially important for migrant families. In addition, heritage language preservation is examined as one very important tool for the educational empowerment of migrant children.
\end{abstract}

\section{Keywords}

gender role, migrant families, educational empowerment

\section{Introduction}

Members of the post-Soviet population abroad have very different ethnic and national backgrounds, but employing the Russian language seems to be one of the significant markers of their group's belonging (Laitin 1998: 15). Their attitudes towards Russian language practices in different environments and the preservation of the Russian language for the next generation appear to be an essential component for understanding the strategies' of educational empowerment in families. According to previous research (Kay 2007), the disposition of gender roles in post-Soviet migrant families tends to be one of the key factors in this process. In addition, exploration of gender-related educational empowerment can be informative and important when investigating social mechanisms which can help people integrate more effectively into local society through educational and social lifts (Sen 1985).

Consequently, our paper will address the following questions: What kind of gender roles have been created in migrant families? What kind of attitudes 
towards education can be found in migrant families? How do mothers influence the educational motivation of children in school? How do fathers' attitudes towards attending ethnic minority complementary schools support the mother tongue preservation? Could this gender balance provide migrant children with new opportunities for development?

Studies of Eastern Europe and post-Soviet countries' migration show a wide range of differences between migrant groups from these countries, but significant similarities and general trends have also been found. One of the most common and important features of this migrant flow seems to be the attitude towards educational empowerment in families and gender role disposition (Heath, McGhee and Trevena 2011).

The research design is usually determined by the research questions and resources (Saunders et al., 2009: 600). The investigation of the impact on gender role disposition on families' educational empowerment among Russian-speaking migrants has broad research perspectives which influence research methodology. We chose a composition of four Russian-speaking school communities attended by parents from Eastern European and postSoviet countries as the main focus of our research. These weekend schools were chosen as the main field works, due to their specific influence on educational empowerment. According to Hornberger (2007), attendance of these schools could be employed as an indicator or criterion of selection of migrant families who are interested in the educational empowerment of their children.

The object of the study is complicated, as gender roles in the schools among Russian-speaking communities require a varied practical approach with qualitative methodology at the core. Our research design merged the following elements together:

- 12 participant observations in the school corridors

- 4 participant observations in the community events organised by Russian schools

- 25 face-to-face ethnographic interviews with parents

Gender relationships inside migrant families are 'socially constructed through the interaction between discursive practices and individual agency' (Stella 2010: 47). In this case, observation and interviews are the most useful research methods as they allow a deeper understanding of behaviour and motivation of migrants. Utilising a mixed methodological approach, we can facilitate a deeper understanding of these gender roles in migrant school society thereby reducing the limitations you would encounter using a single method of data collection. This methodological approach provides us with 
an understanding of the migrant communities and some very important insights which previously were hard to obtain, as usually they are social groups which are 'hard to reach' (Campbell 2010). Previous research shows that migrants tend to avoid direct answers to questions about relations and distribution of powers in their families (Remennick 2012). Quite a large proportion of informants prefer to give normative answers which they believe demonstrate their definition of a 'good migrant.' Prior educational research also encountered some problems in publicly accepted answers to questions about learning, due to the high value of education amount middle class families. People tend to speak in a positive way about education, and mixing participant observation with ethnographic interviews is helpful in clarifying this point and observing how gender roles act out in public places.

Participatory observation allows the gap between how people really bring up their children and what they say they do to be explored (DeWalt, K.M. and DeWalt, B.R. 2002). The main issue for observers is to understand the finer points, which can be helpful to draw a wider picture of social relations and emotions. Gender roles in educational empowerment tend to be sensitive to emotional aspects (Dewaele \& van Oudenhoven 2009) observed during participation in community events. The ethnographic interviews are a method of data collection which can be effectively combined with participatory observation. According to previous research results, migrant families have numerous motivations for educational empowerment of their children (Dailey-O'Cain \& Liebscher 2011). This process is very flexible and deeply immersed in everyday life, and may be based on low levels of reflexivity (Weber and Horner 2012). In this case, parents may face difficulties in answering direct questions, as the ethnographic interview is more flexible and sensitive for respondents, offering more opportunities to tell their own life story, and describe the roles and relationships within families as part of their everyday life (Forsey 2008).

In migrant communities, the question of educational empowerment tends to have strong links with people's attitudes towards the whole educational system. This point was mentioned by groups of parents with diverse educational levels, while the topic of education was a main point in parents' discussions observed in school corridors. Parents try to organise the daily practice of children's education using their own assumptions about effective child development. Decision making of how to prioritise children's activities during the day is important for parents: is it more important for children to visit a sports club or to read a book, or to watch Russian or English cartoons? Making these decisions, migrant parents have to consider the children's opinion but also have to implement their assumptions about what kind of activities are more beneficial for children. Understanding the value of 
education could be considered as the first step in analysing the nature of gender roles in everyday life.

According to our observations and obtained interviews, the majority of migrant parents consider education to be an important and vital part of a child's development which needs no discussion at all. Similar tendencies were found in Polish and Czech migrant communities in the UK (Berrington, Perelli-Harris and Trevena 2015). According to a parental opinion, obligations for their children's development are strongly linked to the time and money which families spend on education for their child. For parents whose children attend complementary schools in Scotland, it appears obvious that they must want to educate their children.

So she is a child, it develops her, however, education is very important for us (Parent, Glasgow).

When some parents decide that education is not valuable, there is no point to discuss this matter with them (Parent, Glasgow).

This attitude towards education as a whole could be classified as the main characteristic of parents whose children attend Russian schools in Scotland. This common point of view from migrant school communities was mentioned more often than others, such as love of Russian culture, or wishing to transfer their values on to children and so on.

$\mathrm{R}$ : What are the common features of parents from Russian schools?

P: Firstly, they are parents who are thinking about the future of their children, for whom education as a whole is a high-level priority in the family. Education is very important for them, they think that education cannot take care of itself, so any extra help is needed (Teacher, Edinburgh).

Probably because of that, I heard that the majority of parents send their children to Russian school not only to study Russian language but also to receive wider knowledge (Parent, Aberdeen).

A follow-up question could be why parents value education so highly. More than half of the parents from Russian schools in Scotland have received higher education. For them, higher education is a part of the family tradition, and they wish their children to have the same academic achievements. This level of well-educated parents is slightly higher in the Edinburgh school and lower in Dundee. However, those parents who do achieve a higher level of education also have some very strong attitudes towards education for their children. From the Russian teachers' point of view, parents who have this attitude had their own learning experiences and can teach and support their child's learning progress. Learning any language - including Russian requires not only communication practice but also the participation of parents when doing writing and grammar homework. 
Parents who spend their time organising educational activities believe that they are investing in the future of their children. From their point of view, professionals will always be in demand, and well-educated people will have better job opportunities in future life.

How are you seeing the future life of your child? I do not know. We only know, not know but wish that she will choose an occupation, and it does not matter what it is. For us, it is important that it is through higher education. As I already said it is our value, my husband and I consider that it gives more chances in life. (Parent, Glasgow)

Education is also assumed to be an asset which is more stable than finance or property, especially in times of crisis. Having experienced difficult periods, migrants are especially sensitive to the issue of stability. Some of them said that finding a more stable and conventional life was one of the primary reasons for moving to another country.

Now everything fails, everything is unstable. Money depreciates, real estate prices still haven't returned to normal after the previous crisis, and already the new one is promised. It is probably worth to put your investment into yourself (Observation in Glasgow Russian School).

Migrant parents who struggle to find appropriate employment, imagine a brighter future for their children which is strongly linked to their occupation and opportunities for self-realisation. Direct evidence of that opinion could not be found in interviews where parents tended to avoid discussing such sensitive subjects. However, observations in school corridors show that people who previously spoke of their difficulties in finding an appropriate job in Scotland often talked about better jobs for their children in the future.

Parents believe that the classic Russian education system provides pupils with more knowledge than the current Scottish one. By sending their children to a Russian school in Scotland, they hope to realise the competitive advantage of their native education. The members of Russian school communities highlight the world status of the Russian education system and its ability to provide people with more knowledge and skills.

The status of Russian education is still great and parents remember that children were taught well. In Europe, people are now returning to that form of education. We all have begun to discuss more and more that a European liberal education leads to the situation that our children lag behind in comparison with Oriental countries, such as China and others (Teacher, Edinburgh).

Parents compare the current academic achievements of children in mainstream Scottish schools with their own past experiences, especially in relation to maths, reading and writing. Parents cannot understand why pupils in primary fourth class do not know what they knew at this age. Maybe, they do not want their children to be equal to them, but they think that 
...if they knew something at age of eight, their children should know more not less at the same age. (Parent, Aberdeen). Yes, I will say honestly that there was an additional push, especially in Maths. In Scottish schools, children at her age do not study Maths (Parent, Aberdeen).

Comparisons between schooling in Russia were a popular topic for discussion among parents when they were waiting for the end of the working day at the Russian school. Parents exchanged their knowledge and experiences of how Scottish mainstream schools work and highlighted differences in methods and educational approaches. The main advantages of Scottish education, from their points of view, were independence and selfmotivation to study, which is encouraged in local children. Migrants wish to integrate local school programmes with some methods of traditional Russian schools. However, referring to Russian schools parents are very rarely told about modern mainstream schools in Russia.

The images of mainstream schools in Russia displayed by parents seem to be a reconstruction of their cultural and educational experience. The main elements of this image are:

- appropriate behaviour in the classroom: paying considerable attention and respecting teachers

- a strong focus on natural scientific subjects

- very clear explanations of any teaching material by teachers to pupils and

- teaching children not only to achieve best results but also teaching how it would be achieved, showing some strategies for learning.

Migrant parents pay special attention to education, not only as a classical social advantage for their children but also at the core of creating their child's own personal identity. According to their beliefs, a thorough education can provide more perspective and vision in life. Some of the migrants who could not find an appropriate place for themselves in Scottish life, considered their own education as a valuable asset for their identity. Achieving a high level of education helped them to feel better socially and, despite their income being lower than the average income of the Scottish middle class, to rank themselves at that level also. A social unbalance was found in mixed families where Russian-speaking wives possessed higher levels of education than their husbands. By teaching children at home, they realise their levels and describe their frustration about their own low demands on their educational potential. 
Russian school communities are not homogeneous in their social and financial resources. Russian speaking people belonging to the middle class are usually more confident in their ability to educate their children and in helping them to shape their future. Their children often attend private Scottish school or state schools in prestigious city districts. In contrast, migrants who do not have sufficient income or social capital said that they cannot give their children the appropriate financial support or include them in social networking which will be beneficial in the future. However, they can present their life experience to their children, offering them more knowledge than a private school.

We are migrants, I cannot provide my child with all of that which I could give him in Russia, but I can devote my life to his education. I can learn with him, take him on various extracurricular activities (Participant observation in Russian school of Glasgow).

To understand gender roles, migrant families can be classified into two groups:

(1) whole migrant families; (2) mixed migrant families. The first type unites family members who are all migrants in host countries. The second type contains partners from whom one is local and marriage with him/her gave the right to the second partners' migration to this country. Those above equal or unequal positions can influence the distribution of power and genderbased stereotypes in families.

In the first group, relationships between partners are more strongly dependant on gender stereotypes which emanate from their countries of origin. According to gender studies in post-Soviet families (Kay 2007), the relationship between genders is not balanced, with the husband assumed to be the more dominant family member with stronger rights to make familyrelated decisions. In this traditional model, the mothers more often play the role of house wives who are responsible for household tasks with the education of children also assumed to come under this heading. Describing their role in families, migrant women highlighted the efforts of the husband as an excuse for their absence in family life. 'Our father is working all day, but I am at home and looking after my small child' (Parent, Glasgow).

However, in Scotland, some of these stereotypes have been experienced in reverse, with the intention of absorbing into the local culture but not the full range as can be expected. The mother's role in the socialisation of children cannot be underestimated in all language and early childhood life. As a result of the mother's education, native language tends to increase the emotional element of communications (Dailey-O'Cain and Liebscher 2011). The dominant language in society is usually implemented later in family life 
when children go to the nursery and school and is employed in official communication with a more formal style (Baker 2014).

If local fathers support the idea of bilingual education for their children and help mothers to preserve their traditional identity, families become more active in educational spaces and are more likely to attend ethnic minority supplementary schools. In these cases, mothers use their own learning experience, teach and support the learning process of their children.

He knows that if Dad comes to put him to bed, he will bring an English book. If mum puts him to bed, a Russian book would be brought. We have a lot of Russian books, and he brings a Russian one himself (Parent, Edinburgh).

These mothers told us that they felt it increases their position of authority in the household dynamics. These women wish to integrate local school programmes with some methods used in ethnic minority schools.

Another point is that education is a core which will be helpful to mould personal identity. According to their beliefs, complex education gives people a better vision. Some mothers, who did not find an appropriate place in British life, consider their education as a valuable asset for their identity. The high level of their education allows them to elevate themselves in society despite their income level. Reading books together with their children, allows parents to create family time where parents have an opportunity to realise their social capital and show their children that even without possessing perfect English, they, nevertheless, know lots of new and interesting things. As such, one of the parents in Dundee in conversation in a school corridor pointed out that she was very glad when her teenage son said: "Mum, I did not have a clue that you are so clever" after discussing with her the book they read together. Before that, her son persistently rejected all of her remarks on the subjects taught in the Scottish school. Having gone through periods of difficulty and crisis, mothers are especially sensitive to the issue of stability. Supporting their children through ethnic minority schools in the UK, they hope to realise the competitive advantage of transnational culture and educational knowledge.

In the modern world, the traditional functioning of gender roles has dramatically shifted. During analysis of educational preferences and choices of educational strategies, it was observed that gender balance affected the integration of migrant children and their families into host countries. Gender balance can be defined as the nature of gender roles in providing successful integration of migrant families into society. Educational empowerment can be recognised as one example of functioning gender balance. The growth of equal participation of both partners in decisions about a child's education can build a more sustainable basis for their education and career perspectives. 
One possible way to strike this balance is the addition of educational decisions within mother's roles, allowing her to realise her educational potential and raise a bilingual child. However, the implementation of this mother's role is only possible if the father's role also accepts the value of bilingual education and supports this intention. In this case, gender balance in decision-making about a child's education can be the key to success in migrant children and their integration into local society. On the contrary, if gender balance cannot be achieved in a migrant family, the risk of difficulties in adaptation among children may increase. For example, the crisis of gender balance may occur when a mother is in favour of bilingual education for her children, but the father is of the opposite view and does not pay sufficient attention to the child's educational needs.

In today's society, children require the special support of their family to maintain a high level of educational motivation and intentions for qualitative education. It is especially important in migrant families where parents' educational levels are quite high but are not demanded or not realised in some reasons. Having gender balance, migrant families receive more opportunities to avoid crossing the poverty line and becoming trapped within vulnerable groups.

\section{Conclusion}

Migrant parents from Eastern European and post-Soviet countries consider education a very important value. From their point of view, heritage language preservation is part of a broader mission. It helps their child's development, providing them with the opportunity to increase the effectiveness of migrant families' integration into Scottish society, using the educational approach from their origin country as a transnational advantage for children. Merging two educational systems - host and country of origin can create special competitive benefits for migrant children. Education can play a role as a social integrator and provider of local social behaviours. In contrast, education with international elements supports transnational activities. Instead of hiding their origin, migrants whose children received bilingual education chose the way to highlight their transnational advantages for local communities through the education process. However, the level of families' activities highly depends on the disposition of gender roles in families.

Special gender balance is established between the roles in mixed families, where fathers are locals and mothers are migrants, in organising and learning motivation. The fathers' roles are providing the integration of migrant families in local society and introducing educational systems for family members. In turn, mothers pay significant attention to children's education and believe that it is a family investment in their future. For the majority of 
migrant families, higher education is part of a tradition, and they hope for the same academic achievements for their children. When teaching children at home, migrant mothers realise their own educational potential and feel less frustrated about their own integration process.

\section{References}

Baker, Fiona Sally (2014) The role of the bilingual teaching assistant: alternative visions for bilingual support in the primary years. International Journal of Bilingual Education and Bilingualism, Volume 17, Issue 3, 2014, pp. 255-271.

Campbell, John (2010) The 'problem' of ethics in contemporary anthropological research. Anthropology Matters Journal, Vol. 12 (1) Available at:

http:/ / www.anthropologymatters.com/index.php/anth_matters/article/v iew/186/306 [Accessed 15.06.2016].

Dailey O., Jennifer and Liebsher, G. (2012) Language attitudes, migrant identities and space. Journal of the Sociology of Language, 212, pp. 91-133

Dewaele, J. and Oudenhoven, J. P. (2009) The effect of multilingualism/multiculturalism on personality: no gain without pain for Third Culture Kids? International Journal of Multilingualism, Vol. 6, No. 4, 2009, pp. 443-459.

DeWalt, K. M. and DeWalt, B. R. (2002) Participant observation: a guide for fieldworkers. Walnut Creek, CA: AltaMira Press.

Forsey, Martin. (2008) Ethnographic interviewing: From conversation to published text. In Walford G. (ed.) How to do Educational Ethnography. London: The Tuffnel Press, pp. 73-93.

Heath, S., McGhee, D. and Trevena, P. (2011) Lost in transnationalism: unraveling the conceptualisation of families and personal life through a transnational gaze. Sociological Research Online, 16(4).

Kay, Rebecca (2007) Introduction: gender, equality and the state from Socialism to Democracy. In Kay, R. (ed.) Gender, Equality and Difference During and After State Socialism. Palgrave Macmillan: Basingstoke, pp. 1-17.

Laitin, David (1995) Identity in Formation: The Russian-Speaking Nationality in the Post- Soviet Diaspora. European Journal of Sociology, Volume 36(2), pp. 281-316. 
Remennick, Larisa (2012), Intergenerational Transfer in Russian-Israeli Immigrant Families: Parental Social Mobility and Children's Integration. Journal of Ethnic and Migration Studies, Volume 38(10), pp. 1533-1550.

Saunders, M., Lewis, P. and Thornhill, A. (2009) Research methods for business students 5th ed. Harlow, Pearson Education.

Sen, Amartya K. (1985) Commodities and Capabilities. Oxford: Elsevier Science Publishers.

Stella, Francesca (2010) The language of intersectionality: researching 'lesbian' identity in urban Russia. In Taylor, Y., Hines, S. and Casey. M. (eds.) Theorizing Intersectionality and Sexuality. Palgrave MacMillan.

Weber, J. and Horner, K. eds. (2012) Introducing multilingualism: A social approach. Routledge, 2012. 